\title{
A Study on the Mechanism between Organizational Support for Development and Turnover Intention of Knowledge Worker-A Perspective of Stress Intervention Theory
}

\author{
Yaru Wang \\ School of Economics and Management, Nanjing University of Science and Technology, Nanjing \\ 210094, China \\ 932543979@qq.com
}

Keywords: OSD, job insecurity, turnover intention, knowledge worker.

\begin{abstract}
The research on the relationship between organizational support for development(OSD) and turnover intention is mostly based on the theory of social exchange and career development theory. However, the study of the two mechanism has not yet reached a consensus and has limited explanatory intensity in changing and uncertain social environment. Managers are questioned about the effectiveness of the organization's developmental support projects. This paper explores the mechanism of OSD and turnover intention with job insecurity (job quality insecurity and job quantity insecurity included) as the intermediation from the perspective of stress intervention theory. Data were mainly collected from knowledge workers of enterprises in Nanjing and Suzhou, jiangsu province, with SPSS 20.0,Amos 17.0 on final 448 valid samples for data analysis. Results shows a obvious negative relationship between OSD and turnover intention of knowledge workers with the partial mediating role of job insecurity. The study provides an original empirical analysis in terms of the impact of OSD on job insecurity, thus shedding light on the mechanisms by which relationships between OSD and turnover intention are produced with a new theory perpective. This has allowed us to obtain more insightful results than those reported in the literature to date. Besides, the study eliminates the doubts about the effectiveness of OSD in the managerial practice. Then we puts forward some management suggestions.
\end{abstract}

\section{Introduction}

There are few direct studies on the developmental support, through the existing literature review, we found that the study of OSD or its similar variables like training, development of human resources practice and turnover mainly has two research mechanism paths. First, based on the social exchange theory to explain the mechanism, most scholars hold the view that when the individual perceives the development of organizational investment, the individual will staying in the organization out of the principle of reciprocity. Thus, OSD and turnover intention is negatively related. Besides, some empirical studies are in line with the interpretation of social exchange theory ${ }^{[1-3]}$.Others explore the relationship between OSD and turnover intention based on the theory of career development, indicating that OSD can enhance the ability of employees to improve their competitiveness in the external market, resulting in an easier staff mobility. So the OSD relates positively to turnover intention. Kraimer et al.(2011) showed that OSD wasn't obviously related to turnover other than firms couldn't provide a proper developmental opportunity forstaffs ${ }^{[4]}$.

Considering the changing context of Chinese society, firm change has transformed long-term stable employment relationships into new employment relationships featuring self-reliance, short-term and flexibility ${ }^{[3-4]}$. Knowledge workers have developed an insecure feeling about work itself and future survival and development, ie. job insecurity ${ }^{[5,6]}$. The increasing work stress leads to increasment of stress response of knowledge workers. Job insecurity is a source of stress ${ }^{[6]}$.Numerous studies have shown that job insecurity is an obstacle-type source of stress that can have a negative impact on job-related attitudes and behaviors (eg,job satisfaction, turnover,turnover intention,etc.) ${ }^{[5]}$. Thus, enterprises need to carry out some human resources practice to reduce the work stress of knowledge 
workers as well as its negative response. OSD is an important human resource strategy to meet the developmental needs of knowledge workers, is also an important stress intervention strategies. It may be improper to comprehend the mechanism of OSD and turnover with social exchange theory under the new employment environment. In addition, the career development theory focuses on the role of OSD in improving employee capacity ignoring the fact that OSD itself conveys the information of long-term employment and staff developmental support. Therefore, we need to find a new explanatory mechanism of OSD and turnover intention of knowledge workers.

The study provides a new mechanism to explain the impact of OSD on turnover intention from the perspective of stress intervention theory. Lorne Sulsky and Carlla Smith (2007) suggested that work stress management strategies acted directly on stress or stress sources and could also act on the process from stressors to stress results ${ }^{[7]}$. OSD is a stress intervention strategy, job insecurity is a source of stress. We want to explore whether OSD can reduce the negative stress response of knowledge workers? Is it possible to reduce the turnover intention of by acting on job insecurity?

\section{Literature review and hypothesis}

\subsection{OSD and Turnover Intention}

There is no consensus on the definition of OSD in literature. Kraimer (2011) defined OSD as employees' overall perceptions that the organization provides programs and opportunities that help employees develop their functional skills and managerial capabilities ${ }^{[4]}$. The OSD consists of two aspects: the perception of the project and the opportunity makes the employee better qualified for the current job and the organization to achieve better performance. Besides, it provides perceptions of functional skills and managerial project support and/or opportunity for employees in the future career development. Scholars generally believe that organizational development opportunities have a negative impact on turnover intention ${ }^{[3,9]}$. Lee and Bruvold (2003), He Huitao, Yuan Yongzhi and Peng Jisheng (2011) argues OSD or organization's developmental investment does not necessarily reduce the turnover of employees ${ }^{[10]}$. Robbins (1997) proposed a typical systematic work stress model that included potential sources of stress, individual differences, stress perception and results of stress ${ }^{[5]}$. The stress source which includes environmental, organizational and personal factors, is an external factor that acts on the individual and causes to produce stress. The results of stress includes physiological, psychological and behavioral responses ${ }^{[8]}$. In the study, job insecurity is produced as an obstacle-type pressure source. We focus only on the negative stress response from it. The turnover model proposed by Price (2001) ${ }^{[11]}$ suggested that work stress affected employees' turnover by negatively influencing employee job satisfaction. Lorne Sulsky and Carlla Smith (2007) shows stress management strategies can not only act on the process of stressors to stress results, but also directly act on source of stress or stress results ${ }^{[7]}$. Scholars also shows turnover intention is an effective variable in predicting turnover ${ }^{[12]}$.As a strategy to ease stress of knowledge workers, OSD will reduce this negative stress response. According to the theory of stress intervention, OSD can act directly on the stress response itself to relieve the stress response ${ }^{[7]}$. Thus, we propose:

H1: OSD relates negatively to turnover intention of knowledge workers.

\subsection{OSD and Job Insecurity}

Through the literature analysis, it can be found that organizational support and other social support are regarded as important predictors of job insecurity. They have a negative impact on turnover intention ${ }^{[11-13]}$. Johnny Hellgren, Magnus and Rosenblatt (1984) argued that job insecurity was a sense of powerlessness that individuals continued to work in a threatened working environment. The definition of job insecurity was too narrow in past reviews, ignoring the deterioration of employment conditions and the reduction of career opportunities. According to existing researches, we consider job insecurity as a source of stresss ${ }^{[6]}$. It's a kind of concern about the stability and quality of the employment relationship of knowledge workers in a changing environment. The scholar argues that job insecurity includes two dimensions: job quality insecurity and job quantity insecurity. The former reflects employee concerns about loss of job, while the latter reflects their perception of the 
damage/threat to the quality of the employment relationship [13], including the lack of career opportunities and deterioration of working conditions. Empirical studies have found that organizational support is significantly associated with job insecurity ${ }^{[4-5]}$. There is no direct empirical study of OSD and job insecurity.

In the study, job insecurity is an obstacle-type source of stress ${ }^{[6]}$. OSD is one of the stress intervention strategies that can act directly on stressors ${ }^{[7]}$. In other words, OSD conveys the organization's long-term employment and support for the promotion of knowledge workers, when they perceive the signal, they will be expected to have potential opportunities of owning the current work, getting pay growth and promoted in future. Then, it will reduce their perception of job insecurity. Thus, we propose:

$\mathrm{H} 2$ : OSD relates negatively to job insecurity [job quality insecurity (2a), job quantity insecurity (2b) ]of knowledge workers.

\subsection{Mediating Role of Job Insecurity}

Empirical studies have shown a significant positive relationship between job insecurity and turnover intention ${ }^{[8,13]}$. The job insecurity, as an obstacle type source of stress, cause employees to have negative behavior or attitude and do harm to the organization. Therefore, the organization should adopt a corresponding human resources policy to reduce the negative impact of job insecurity. Scholars have pointed out that the negative consequences of eliminating and weakening job insecurity can be analyzed not only by adjusting the variables to intervene in the process of job insecurity and its negative results but also by influencing antecedents of job insecurity ${ }^{[13-14]}$. When knowledge workers perceive the signal of OSD, the sense of insecurity at work will be reduced or mitigated, and the negative attitude will be reduced. Robbins (1997) also indicated that the stress source can act directly on the stress process. From the view of stress intervention theory, OSD is a kind of stress intervention strategy, job insecurity is an obstacle-type source of stress, and the turnover intention is a stress response. According to "stress intervention strategy-stress source- stress response", the stress intervention strategy can reduce the stress response by relieving or eliminating the stressor ${ }^{[7]}$. Thus, we propose:

H3: Job insecurity [job quality insecurity (3a), job quantity insecurity (3b)] mediates the relationship between OSD and the turnover intention of knowledge workers.

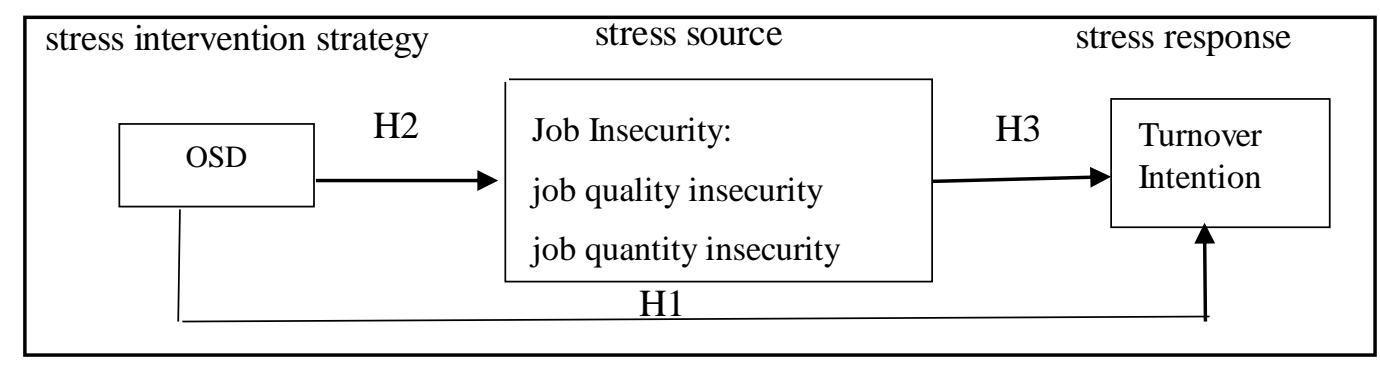

Fig. 1 the Model of OSD and Turnover Intention

\section{Method}

Data The study takes the form of anonymous questionnaire survey targeted to knowledge workers of enterprise. Questionnaires were mainly distributed in Nanjing and Suzhou enterprises. We obtained 520 responses and a final total of 4448 valid questionnaires with effective rate of $86.15 \%$.The questionnaire is divided into four parts. In order to avoid neutral answers, the questionnaire uses the six-point scale method. The statements were scored on six-point Likert-type scales $(1=$ "very disagree"; $6="$ Very agree"). The Cronbach's Alpha of all the variables was 0.608 .

Measure Six items measuring OSD were adapted from Kraimer et al. (2011) ${ }^{[4]}$.Job insecurity was measured by seven statements adapted from Hellgren, Sverke \& lsaksson $(1999)^{[13]}$. The items are divided into two dimensions, which the job quality insecurity contains four items, job quantity insecurity includes three items. Four items measuring turnover intention were adapted from Gilad Chen et al.(2011) ${ }^{[14]}$. For this study we used demographic variables as our control variable, including gender, age, marital status, educational background, formal working years, working years of current 
enterprise, the nature of enterprises and enterprise industry with the classification of the enterprise classified by the National Bureau of Statistics.

\section{Results}

\subsection{Reliability and Validity Analysis}

The distribution of sample is more uniform (male $49.3 \%$, female $50.7 \%$ ) covering most of the industry. The results show that all the entries are analyzed by non-single factor with SPSS 20.0, it reveales the existence of three distinct factors with a maximum variance explained by one single factor of $33.21 \%(<40 \%)$, suggesting the survey data do not have serious problem of common method deviation.

In the study, we use variance inflation factor (VIF) for collinearity analysis. The all VIF is below 10 in all the regression equations indicating that the degree of collinearity of the data is within a reasonable range. The results show a $\chi^{2} / \mathrm{df}$ of $3.52, \mathrm{CFI}=.927, \mathrm{IFI}=.928$, RMSEA=.075, NFI=.8902 by Amos 17.0 for confirmatory factor analysis (CFA), suggesting a good construct validity.

\subsection{Correlation and Regression Analysis}

The correlation analysis of the all variables shows that gender is negatively correlated with turnover intention ( $\beta=-.141, \mathrm{P}<.01)$, suggesting that male mobility is higher than women. Age and the working years are negatively correlated with turnover intention. There is a significant negative correlation between OSD and turnover intention $(\beta=-.470, \mathrm{P}<.01)$. And OSD has a negative correlation with job insecurity $(\beta=-.540, \mathrm{P}<.01)$, job quality insecurity $(\beta=-.636, \mathrm{P}<.01)$ and job quantity insecurity $(\beta=-.280, \mathrm{P}<.01)$. There is a significant positive correlation between job insecurity (job quality insecurity and job quantity insecurity) and turnover intention $(\beta=.627, \mathrm{P}<.01)$.

The direct effects. The regression analysis of OSD and turnover intention shows the explanatory intensity of $\mathrm{M}_{1}$ (adding OSD besides control variables) is higher than $\mathrm{M}_{0}\left(\Delta \mathrm{R}^{2}=.225\right)$. ie. OSD relates significant negatively to turnover intention $(\beta=-.480, \mathrm{P}<.001)$. Thus, $\mathrm{H} 1$ is supported. Presuming $\mathrm{M}_{2}$ only involves control variables with job insecurity as the dependent variable, having an $\mathrm{R}^{2}=.018$ and $\mathrm{F}=.889$. We add OSD in $\mathrm{M}_{3}$, then get an $\mathrm{R}^{2}=.305$ and $\mathrm{F}=19.179(\mathrm{P}<.001) . \mathrm{M}_{3}$ increases the explartory intensity $\left(\Delta \mathrm{R}^{2}=.287\right)$. OSD relates significant negatively to job insecurity $(\beta=-.541, \mathrm{P}<.001), \mathrm{H} 2$ is supported. $\mathrm{M}_{4}$ and $\mathrm{M}_{5}$ are models with dependent variables of job quality insecurity. $\mathrm{M}_{4}$ represents a model only involving the control variables having an $\mathrm{R}^{2}$ of .032 and $\mathrm{F}=1.587$. When added OSD into $\mathrm{M}_{5}$ has an $\mathrm{R}^{2}$ of .425 and $\mathrm{F}=32.276(\mathrm{P}<.001)$, the explanatory intensity of model is significantly enhanced. Therefore, $\mathrm{H} 2 \mathrm{a}$ is supported $(\beta=-.634, \mathrm{P}<.001)$. Presuming that $\mathrm{M}_{6}$ and $\mathrm{M}_{7}$ are models with dependent variables of job quanity insecurity, the explanatory intensity of the $\mathrm{M}_{7}$ is obviously enhanced $\left(\Delta \mathrm{R}^{2}=.080\right)$ indicating that OSD has a negative impact on job quantity insecurity $(\beta=-.285$, $\mathrm{P}<.001)$. Therefore, $\mathrm{H} 2 \mathrm{~b}$ is supported.

The mediating effects. The regression results of mediating role (ie.job insecurity) are as below. $\mathrm{M}_{1}$ is the model involving independent variable of OSD. $\mathrm{M}_{8}$ is the model adding job insecurity $\left(\mathrm{R}^{2}=.473, \mathrm{P}<.001\right), \Delta \mathrm{R}^{2}=.196(\mathrm{P}<0.05)$, the coefficient of OSD is still significant $(\beta=-.192, \mathrm{P}<.05)$. Thus, there is a partial mediating effect of job insecurity $(\beta=.625, \mathrm{P}<.001)$. So H3 is supported. $\mathrm{M}_{9}$ is the model after adding job quality insecurity $\left(\mathrm{R}^{2}=.352, \mathrm{P}<.001\right), \Delta \mathrm{R}^{2}=.075$. We can see the coefficient of OSD is still significant $(\beta=-.251, \mathrm{P}<.001)$. So there is a partial mediating effect of job quality insecurity $(\beta=.360, \mathrm{P}<.001), \mathrm{H} 3 \mathrm{a}$ is supported. $\mathrm{M}_{10}$ is the model involving the job quantity insecurity $\left(\mathrm{R}^{2}=.491, \mathrm{~F}=38.221, \mathrm{P}<.001\right)$, the explanatory intensity of $\mathrm{M}_{10}$ is higher than that of the $\mathrm{M}_{1}\left(\Delta \mathrm{R}^{2}=.213\right)$, the coefficient of OSD is still significant in $\mathrm{M}_{10}(\beta=.485, \mathrm{P}<.001), \mathrm{H} 3 \mathrm{~b}$ is supported. In summary, hypothesis are all supported.

\section{Discussion}

This study enriches the study of OSD and opens up a direct empirical study of OSD and job insecurity. What's more, this paper provides a new perspective for understanding mechanism of OSD and turnover in context of changing environment. 
First, OSD is beneficial for both enterprises and employees. From the perspective of demand theory, OSD increases the accumulation of human capital of knowledge workers, and meet the demand of knowledge workers for their own development. Therefore, OSD is an effective means of managing knowledge workers, thus conducive to the ultimate realization of staff and enterprise development. Second, the sustainable development of enterprises lies on internal training of talent and internal talents pool. OSD can be regarded as a good way to invest in human capital, this in turn will undoubtedly enhance the ability of knowledge workers, ultimately value added. In practice, enterprises nowadays pay more and more attention to OSD including enterprise training, the development of human resources practice, OSD and so on, they all belong to human capital investment. Third, according to empirical results, managers can consider certain practices or developmental support projects to intervene in the quality and quantity of job insecurity to indirectly reduce the turnover of knowledge workers.

\section{Acknowledgments}

This work was financially supported by: 1.National Natural Science Foundation of China. The Cross-layer Model of Strategic Change to Implement in Mutation Environment-Based on the Change of Cognitive Perspective (71672084) .2.Science and Technology Department of Jiangsu Province. Research on Evaluation of Competitiveness of Industrial Entrepreneurs in Jiangsu Province (BR2016055).

\section{References}

[1] Jackson S E, Schuler R S, Jiang K. An aspirational framework for strategic human resource management [J]. The Academy of Management Annals. 2014(1): 1-56.

[2] Allen D G, Shore L M, Griffeth R W. The role of perceived organizational support and supportive human resource practices in the turnover process [J]. Journal of Management. 2002, 29(1): 99-118.

[3] Robbins, Jia Qi, Li Yuan, et al. Organizational Behavior [M]. 12th edition. Renmin University of China Press, 2008.

[4] Kraimer E, Seibert J, Wayne C, Liden Robert, et al. Antecedents and outcomes of organizational support for development: the critical role of career opportunities [J]. Journal of Applied Psychology. 2011(3): 485-500.

[5] Robinson M. Job insecurity in the new model of public employment.[J]. Economic \& Labour Relations Review. 1996, 7(2): 262-284.

[6]Sverke M, Hellgren J. The nature of job insecurity: Understanding employment uncertainty on the Brink of a New Millennium [J]. Applied Psychology. 2002, 23-42.

[7] Smith C, Sulsky L. Work stress [M]. Beijing: China Light Industry Press, 2007. Liu Jun, Liu Xiaoyu, Ren Bing. Staff turnover: employment relationship under the framework of tracking research [J]. Management of the world. 2007 (12): 88-95.

[8] Ashford S J, Bobko P. Content, cause, and consequence of job insecurity: A theory-based measure and substantive tes t[J]. Academy of Management Journal. 1989, 32(4): 803-829.

[9] Lee C H, Bruvold N T. Creating value for employees: investment in employee developmen [J]. International Journal of Human Resource Management. 2003, 14(6): 981-1000.[15]

[10] He Huitao, Yuan Yongzhi, Peng Jisheng. Investment in staff development worth it? Development of human resources practice on employee knowledge sharing and turnover intention [J]. Management Review. 2011 (01): 75-84.

[11] Price J L. Reflection on the determinants of voluntary turnover [J]. International Journal of Manpower. 2001, 22(7): 600-624.

[12] Batt R. Managing customer services: Human resource practices, quit rates, and sales growth [J]. The Academy of Management Journal. 2002, 45(3): 587-597.

[13] Hellgren J, Sverke M, Isaksson K. A two-dimensional approach to job insecurity: Consequences 
for employee attitudes and well-being [J]. European Journal of Work and Organizational Psychology. 1999, 8(2): 179-195.

[14] Chen G, Ployhart R E, Thomas H C, et al. The power of momentum: A new model of dynamic relationships between job satisfaction change and turnover intentions [J]. Academy of Management Journal. 2011, 54(1): 159-181. 